\title{
Investigação biomédica e vulnerabilidade: um estudo acerca da responsabilidade dos profissionais da saúde nas pesquisas envolvendo seres humanos"
}

\author{
Biomedical research and vulnerability: a study on responsibility \\ of health professionals in research involving human beings
}

Angelita Maria Maders*

\begin{abstract}
Resumo
O presente artigo é resultado de uma pesquisa bibliográfica que, utilizando uma metodologia baseada no modelo hipotético-dedutivo, objetivou fazer uma reflexão acerca dos avanços biotecnológicos frente à vulnerabilidade dos sujeitos submetidos às pesquisas que envolvem seres humanos na América Latina, mormente no que se refere aos limites da atuação dos profissionais da saúde e sua responsabilização. Ele parte do pressuposto de que não há como separar a ciência da ética. Para fins do trabalho, são considerados profissionais da área da saúde todos aqueles envolvidos nas investigações científicas, desde o cientista pesquisador até os integrantes dos comitês de ética da pesquisa que aprovam ou não os projetos investigatórios. Constatou-se que, no decorrer do desenvolvimento social houve a elaboração de diversos documentos para estabelecer limites à atuação dos profissionais da saúde na investigação biomédica, inclusive de natureza internacional, os quais, contudo, tem-se mostrado insuficientes para a proteção dos direitos dos sujeitos envolvidos. Concluiu-se que os referidos profissionais devem ter sua conduta pautada pelos Códigos de Ética relativos à sua profissão, mas também regulamentada por meio de um documento de natureza jurídica que leve em consideração a diversidade e a vulnerabilidade latino-americana para viabilizar sua responsabilização e a consequente proteção das pessoas envolvidas.
\end{abstract}

Palavras-chave: Pessoal de Saúde. Experimentação Humana. Vulnerabilidade em Saúde. Ética.

\begin{abstract}
The present article is the result of a bibliographical survey that seeks to present, by using a methodology based on the hypothetical-deductive method, to present a reflection on the biotechnological advances taking in consideration the vulnerability of the individuals submitted to researches involving human beings in Latin America, especially regarding the limitations of health professionals' actions and their liability. The basis of this works is the assumption that it is impossible to separate science from ethics. For this work's purposes we consider health professionals to be everyone involved in scientific investigations, from the scientist responsible for the initial project to the members of the Ethics Committees which have the power either to approve or not research projects. It has been noticed that recent social developments created a great number of documents aiming at establishing boundaries to the actions of health professionals in the biomedical investigation field, documents which however have showed themselves incapable of protecting the rights of the individuals involved. The conclusion extracted from the present research is that health professionals must have their actions guided and limited by the Ethics Codes related to their professional areas but also that there must be a legal regulation that takes into account the diversity and vulnerability of Latin Americans in order to make possible holding referred professionals liable and thus protecting the individuals involved.
\end{abstract}

Keywords: Health Personnel. Human Experimentation. Health Vulnerability. Ethics.

DOI: $10.15343 / 0104-7809.20143802228236$

\# Este artigo é resultado de parte das pesquisas realizadas para o Pós-doutorado junto à Universidade de Santiago do Chile.

* Universidade Regional Integrada do Alto Uruguai e das Missões - URI e Universidade Regional do Noroeste do Estado do Rio Grande do Sul - UNIJUÍ. E-mail: angmaders@hotmail.com

A autora declara não haver conflitos de interesse. 


\section{INTRODUC̣ÃO}

É estranho considerar que a ciência, por ter como finalidade a descoberta de inventos que venham em benefício dos seres humanos e possuir um crédito como transmissora da verdade oficial, necessite de ética, assim como parece difícil pensar que os cientistas, que têm por missão descobrir e compreender as causas dos fenômenos, possam faltar com a verdade ou trabalhar contra os ideais da ciência e em prol de interesses próprios ou dos da indústria que os financia. Por isso se diz que eles têm uma dupla responsabilidade: uma como profissional e a outra como ator social frente ao prestígio que levam consigo, porque os resultados de suas investigações afetam a todos.

A investigação biomédica objetiva produzir conhecimentos que contribuam para a melhoria da qualidade de vida da população e implica a inclusão de seres humanos nos ensaios clínicos, já que as pesquisas incluem aspectos relacionados aos diagnósticos, profilaxias e tratamento de doenças. A participação das pessoas em diferentes fases do desenvolvimento das pesquisas ${ }^{a}$ para testar novas drogas e procedimentos pode gerar diferentes conflitos éticos, tangencialmente à proteção dos participantes frente à sua vulnerabilidade, bem como responsabilidades aos profissionais de saúde envolvidos nas investigações, em virtude do que não é possível separar a ciência da ética.

Durante o desenvolvimento da ciência, muitos exemplos de má prática científica ocorreram. Alguns profissionais foram penalizados; outros permaneceram impunes; tudo em nome do progresso. Em decorrência de fatos que atentaram contra os direitos humanos e chegaram ao conhecimento público, diversas organizações internacionais elaboraram documentos assinalando pautas éticas para a proteção das pessoas que se submetem a estudos e investigações clínicas, assim como diferentes Estados já legislaram a respeito. Dentre essas regulamentações está a criação de Comitês de Ética em Pesquisa, que têm importante função na avaliação dos aspectos éticos e científicos envolvidos na condução das pesquisas para minimizar os riscos a que poderão estar expostos os participantes. Mas, ainda assim, permanece a incerteza e a falta de uma legislação mais cogente acerca do tema, especialmente se considerado que ela não deve se limitar a um território, já que os conflitos dessa ordem não possuem fronteiras.

Os Comitês de Ética em Pesquisa são formados por integrantes de diferentes áreas do conhecimento e representantes da sociedade civil para evitar a exploração e garantir maior representatividade social e respaldo comunitário para o desenvolvimento da ciência. Todavia, não somente eles têm uma importante função nas investigações que envolvem seres humanos, mas em especial os investigadores e os profissionais da saúde que conduzem e estão envolvidos nas pesquisas, cuja responsabilidade se pretende abordar aqui frente às populações vulneráveis da América Latina, pois, como prática social, a investigação científica também deve estar sujeita a controle.

Neste artigo, refletiu-se, então, acerca do agir dos profissionais da área da saúde na condução de pesquisas com seres humanos. A discussão segue dividida em duas partes. Na primeira, é trabalhada a vulnerabilidade nos países latino-americanos, para, em seguida, abordar-se a responsabilidade dos investigadores e profissionais da saúde envolvidos nas pesquisas com seres humanos e a necessidade de elaboração de um documento para estabelecer limites ao seu agir.

\section{MÉTODO}

Trata-se de um estudo bibliográfico que utiliza o método hipotético-dedutivo para, fazendo uma revisão da literatura acerca do tema, refletir acerca dos avanços biotecnológicos frente à vulnerabilidade dos sujeitos submetidos às pesquisas que envolvem seres humanos na América Latina, mormente no que se refere aos limites da atuação dos profissionais da saúde e sua responsabilização. Para isso, segue-se uma linha de raciocínio segundo a qual, em face

\footnotetext{
a. A investigação clínica farmacológica divide-se em fases. Há uma etapa pré-clínica que não necessita da intervvenção de seres humanos, mas computadores, tecidos. "A chamada fase I ensaia o produto para provar sua toxidade e emprega amostras pequenas de sujeitos sãos. A fase II estuda segurança, eficácia e bioequivalência em grupos pequenos de doentes. A fase III envolve estudos amplos para demonstrar eficácia, segurança e refinar indicações. A fase IV, posterior ao lançamento público e parte da difusão de marketing, envolve milhares de pacientes e tenta identificar efeitos secundários, novas indicações ou afiançar presença entre os médicos"1.
} 
da insuficiência de conhecimentos disponíveis sobre o assunto para a explicação do problema acerca da responsabilidade dos profissionais da saúde nas pesquisas biomédicas envolvendo seres humanos, são formuladas hipóteses, para as quais são deduzidas consequências, que seguem testadas no decorrer da pesquisa.

\section{RESULTADOS}

Em cada país latino-americano é distinto o grau de vulnerabilidade de seus habitantes. Nas pesquisas, nem todos os participantes se encontram igualmente protegidos, pois são desiguais em diferentes aspectos: condições de vida, falta de equidade no acesso aos serviços de saúde, de justiça, educação. Se o participante for tratado e respeitado como sujeito de direitos e participar do processo investigativo de forma consciente e ativa compartilhando as informações, pode-se ter uma pesquisa ética e uma ciência efetivamente solidária, pois, em uma sociedade democrática, a participação das pessoas e o compartilhamento das informações que têm a ver com o destino do grupo é importante, já que tem a ver com a cidadania. Tangencialmente ao tema que se abordou neste artigo, a comunhão dos conhecimentos obtidos nas pesquisas entre os participantes, pesquisadores e profissionais da área da saúde implica maturidade para a tomada de decisões que afetarão não somente os investigados, mas a sociedade como um todo, pois a ela se destina o progresso da ciência.

É muito importante que os profissionais da saúde, na medida em que suas atividades e responsabilidades se expandem, tenham uma visão holística e consciência de que "tudo o que é tecnicamente possível deve ser eticamente considerado" (p. 2) ${ }^{2}$, como referem Lorda e Cantalejo, pois eles têm responsabilidades diretas com a vida humana, de modo que devem promover o bem-estar dos pacientes e protegêlos de possíveis danos, no que o diálogo com os pacientes e participantes das pesquisas pode contribuir sobremaneira. Esse diálogo implica reconhecimento mútuo das pessoas participantes que pretendem compartilhar e auferir informações e conhecimentos para que os investigados compreendam, de acordo com suas capacidades, a situação na qual estão envolvidos. Implica, ainda, conferir-lhes autonomia e participação ativa no desejado processo terapêutico.

Os profissionais da saúde têm por responsabilidade reduzir a vulnerabilidade dos participantes das pesquisas garantindo-Ihes autonomia e dignidade. Além disso, eles não devem esquecer que as pessoas culturalmente privilegiadas ou aquelas que detêm o conhecimento de determinada matéria têm o dever moral de fornecer condições mais adequadas ao outro vulnerável, o que seria a expressão de uma ética da solicitude, de solidariedade.

\section{DISCUSSÃO}

\section{A vulnerabilidade nos países latino-ame- ricanos $\mathrm{e}$ as investigações biomédicas}

A busca pela cura de doenças passa pelo desenvolvimento de pesquisas que utilizam seres humanos, o que é motivo de preocupação da sociedade e também dos próprios profissionais envolvidos, por se tratar de uma questão ética. O dilema reside nos limites da experimentação imposta pelo desenvolvimento científico e o respeito aos direitos humanos. Por isso, a discussão ética aplicada à saúde e aos profissionais dessa área é importante e ganhou diferentes interlocutores de diversas áreas do conhecimento, já que esse tipo de intervenção é de domínio público por ter a ver com a vida e a morte dos cidadãos.

Pesquisas não-éticas foram realizadas com seres humanos ao logo da história e alcançaram seu apogeu durante a Segunda Guerra Mundial. Elas utilizaram como objeto das investigações pessoas consideradas "inferiores" por razões sociais, econômicas, étnicas e culturais. A situação não é diversa na atualidade, pois as grandes indústrias farmacêuticas e laboratórios multinacionais, por exemplo, conduzem experimentos com pessoas para testar medicamentos e vacinas que estão aprimorando, preferencialmente em países em desenvolvimento, a exemplo da América Latina, cuja população é mais vulnerável e, por isso, submete-se às experiências por diferentes razões, dentre elas a esperança de ter acesso ao medicamento.

Vulnerabilidade é uma palavra de origem latina, vulnus (eris), sinônimo de ferida. Ela significa a 
possibilidade de ser ferido, excluído, segregado, marginalizado ${ }^{3}$ e seu conceito possui três sentidos distintos na doutrina: ela é considerada como uma condição humana, como característica particular de pessoas e grupos ou como princípio ético internacional. O primeiro sentido leva em conta a fragilidade da existência humana; o segundo toma em consideração, especialmente, o âmbito das pesquisas biomédicas envolvendo seres humanos e a defesa destes frente a eventuais abusos. Em relação a esse sentido, as Diretrizes Éticas Internacionais para a Pesquisa Biomédica em Seres Humanos do Conselho de Organizações Internacional de Ciência Médicas (CIOMS-2002) entendem como vulneráveis aqueles que têm a capacidade ou liberdade para consentir ou abster-se de consentir diminuída. O terceiro sentido tem base na Declaração Universal sobre Bioética e Direitos Humanos da Unesco ${ }^{4}$ que enuncia, em seu artigo $3^{\circ}$, a obrigatoriedade do respeito à vulnerabilidade humana e à integridade pessoal, tanto que grupos e indivíduos vulneráveis devem ser protegidos sempre que a vulnerabilidade humana for agravada por circunstâncias diversas.

A Declaração de Helsinque descreve a vulnerabilidade em seu parágrafo 19 quando refere que:

Alguns grupos e indivíduos sob investigação são particularmente vulneráveis e têm uma probabilidade aumentada de ser lesados ou de ocorrência de danos adicionais. Todos os grupos e indivíduos vulneráveis necessitam de proteção que lhes seja especificamente dirigida ${ }^{5}$.

A vulnerabilidade, como concebe Kottow, é uma dimensão antropológica essencial da existência humana, inerente à condição humana (vulnerabilidade primária), comum a todas as culturas, pois ser vulnerável significa ser ou "estar suscetível a, ou em perigo de, sofrer danos" ( $p$. $72)^{6}$. Além disso, os seres humanos estão predispostos a diferentes tipos de vulnerabilidade, seja pela própria morte, seja pela própria condição de existência, decorrentes de fatores sociais, a exemplo da pobreza, falta de educação (vulnerabilidade secundária), que os tornam ainda mais vulneráveis do que pelo simples fato de existirem.

As Diretrizes Éticas Internacionais do CIOMS definem como pessoas vulneráveis aquelas "pessoas relativa ou absolutamente incapazes de proteger seus próprios interesses. De modo mais formal, podem ter poder, inteligência, educação, recursos e forças insuficientes ou outros atributos necessários à proteção de seus interesses" ${ }^{\prime 7}$. A vulnerabilidade em questão identifica-se como uma capacidade limitada ou uma liberdade diminuída para consentir na pesquisa ou até mesmo para participar dela, seja por não ter experiência ou capacidades adequadas para examinar os termos éticos e científicos da pesquisa proposta e ou opções de tratamento fora do ambiente da pesquisa. Um fator que aumenta a vulnerabilidade em países em desenvolvimento é a ausência de mecanismos de supervisão e controle das pesquisas, inclusive para impor sanções àqueles pesquisadores que violarem leis, regulamentos ou padrões éticos durante a condução das investigações, o que torna todos os sujeitos da pesquisa potencialmente vulneráveis ${ }^{8}$.

Na América Latina, a vulnerabilidade em razão da simples existência humana é agravada em razão da situação econômica e social dos países que a integram e, na área da saúde, em virtude da falta de investimentos por parte do Poder Público na prevenção e no combate às doenças. Por isso, entende-se que a população latino-americana está mais vulnerável nessa área e, portanto, fica à mercê dos grandes laboratórios que conduzem suas pesquisas e que não veem na saúde um direito de todos e um dever do Estado, como previsto na Constituição Federal brasileira de 1988, mas como um produto lucrativo a ser comercializado e explorado.

As pesquisas que envolvem seres humanos têm maior probabilidade de gerar conflitos éticos em países em desenvolvimento quando os pesquisadores e profissionais da saúde envolvidos são patrocinados por um país industrializado ou por uma grande companhia farmacêutica, isso em virtude do baixo nível de escolaridade ou de desconhecimento acerca dos conceitos científicos modernos, bem como de sua pobreza e impotência frente às perspectivas de benefício terapêutico das investigações ${ }^{8}$.

No Brasil, a situação de vulnerabilidade das pessoas é alarmante em relação aos países desenvolvidos, pois, no meio sanitário, ele sofre com a falta de equidade, utilizando tecnologias avançadas em diversas áreas da medicina,

तิ


a exemplo do tratamento de cardiopatias, mas referidas tecnologias não são acessíveis a todos os brasileiros, apenas àqueles que dispõem de recursos financeiros para pagar por sua utilização. Isso significa que poucos têm condições de receber um atendimento de qualidade, enquanto que a maioria da população recebe um atendimento precário, superlotado, carente de equipamentos e sem grandes recursos tecnológicos, que é fornecido pelo sistema de saúde pública. Na Bolívia, por sua vez, a situação é ainda pior, pois o país sequer dispõe de um sistema público de saúde ${ }^{9}$.

Considerando que a ciência tem por objetivo justamente minimizar ou combater essas vulnerabilidades, não se pode concebê-la criando ou expondo os sujeitos a novas e mais complexas formas de vulneração. O progresso social e científico, contudo, demonstra que cada vez mais isso vem ocorrendo, pois os avanços tecnocientíficos, em especial na área da biomedicina, no âmago de libertar as pessoas das doenças, tem-nas exposto a outras formas de vulnerabilidade mais específicas, de modo que as vulnerabilidades secundárias estão mais suscetíveis de acometer a humanidade ${ }^{10}$ quanto menos desprovidas de condições de desenvolvimento forem as populações, como é o caso dos países da América Latina na atualidade.

Os documentos internacionais elaborados para tentar proteger os vulneráveis frente às pesquisas que os incluam como participantes para testar o uso de drogas e ou procedimentos médico-clínicos trazem como palavras de ordem o respeito às pessoas, o consentimento informado e esclarecido dos pacientes, a voluntariedade e autonomia, a justiça social com a distribuição dos benefícios e riscos das pesquisas entre os participantes e os países onde foram desenvolvidas as investigações.

O Código de Nuremberg, datado do ano de 1947, foi pioneiro com suas contribuições para trazer uma nova luz às questões relacionadas à prática científica, o que pode ser resumido em seu primeiro parágrafo como sendo condição absoluta para a experimentação sobre seres humanos o consentimento livre do sujeito que se submete à investigação. Além disso, ele já previa a responsabilidade do investigador sobre a obtenção do referido consentimento, bem como sobre a evolução e desenvolvimento da pesquisa.

O Relatório Belmont (1978) definiu três princípios éticos básicos que devem nortear a realização das investigações que envolvem seres humanos: o respeito (consentimento informado), a beneficência (balanço entre os riscos e os benefícios da pesquisa) e a justiça (distribuição equitativa da participação nas investigações). Uma investigação ética deve, pois, harmonizar o apropriado, o bom e o justo para a sociedade.

As Pautas Éticas Internacionais para Investigação e Experimentação Biomédica em Seres Humanos (CIOMS / OMS) divulgadas em 1982, atualizadas em 1993 e 2002, dirigem sua atenção às pesquisas desenvolvidas por países desenvolvidos em países em desenvolvimento, com populações vulneráveis ${ }^{11}$.

Esses documentos foram adotados por diversos países, inclusive na América Latina, onde tiveram de ser reinterpretados e adaptados, e serviram de pauta para a regulação interna. Em termos de Mercosul, por exemplo, foi posta em acordo a Resolução n. 129/1996, intitulada "Boas Práticas Clínicas", na qual restou assinalado que

(...) na investigação em farmacologia clínica, a autorização, o acompanhamento e as responsabilidades dos investigadores e dos patrocinadores são requisitos éticos indispensáveis. Aponta a necessidade de obter informação pré-clínica e clínica dos fármacos em investigação como forma de garantir a proteção dos participantes incluídos nas etapas seguintes da experimentação (p. $225)^{11}$.

A Declaração de Helsinque (1964), por sua vez, complementou o texto do Código de Nuremberg ampliando a proteção dos participantes das pesquisas, inclusive com a necessidade de submissão de todos os projetos de pesquisa à avaliação e aprovação de um comitê de ética. Ocorre que ela sofreu diversas revisões (1975, 1983, 1989, 1996, 2000, 2002, 2004, 2008 e 2013) e, na penúltima, acabou aprovando um abrandamento dos rigorosos controles anteriormente previstos em favor dos interesses das indústrias farmacêuticas e em detrimento dos interesses dos seres humanos, especialmente nos países em desenvolvimento, que são mais vulneráveis, a 
exemplo da América Latina, uma região considerada de maior desigualdade no mundo pela Comissão Econômica para a América Latina e Caribe (CEPAL). Fala-se de um duplo standard, ou seja, de padrões éticos diferenciados para protocolos de pesquisa que seriam justificados em função da diversidade socioeconômica dos diversos países a serem alvo das pesquisas.

Há argumentos favoráveis a esse double standard como também contrários. Os favoráveis não veem qualquer "desvio ético em utilizar placebo nos ensaios clínicos em países pobres, ainda que existam tratamentos comprovadamente eficientes para as doenças em teste, desde que estes tratamentos não estejam disponíveis para a população de onde os sujeitos são recrutados"12, pois se estaria oferecendo uma chance de tratamento àqueles que fossem sorteados para integrar o grupo teste, sem aumentar os riscos daqueles que estivessem no grupo controle, além de oferecer assistência médica, fornecimento de equipamentos para as instituições de saúde desses países e formação de recursos humanos.

Os contrários alegam que a falta de acesso a medicamentos não é uma desigualdade natural, mas exclusão social presente em países pobres, em decorrência de suas condições políticas e econômicas. Além disso, a permissão do uso de placebo constituiria um estímulo para que as empresas farmacêuticas mantenham preços altos de forma a dispor sempre de grupos populacionais sem acesso a medicamentos, a fim de realizar ensaios clínicos com conclusões mais rápidas e a menores custos $^{12}$.

O Brasil contestou a interpretação adotada quanto à possibilidade de uso de placebo em pesquisas envolvendo seres humanos e, em outubro de 2005, em Córdoba, na Argentina, foi rechaçada a referida versão da Declaração de Helsinque e aprovado que seriam utilizados, na América Latina, como referência ética e normativa para o assunto, os princípios da Declaração Universal sobre Bioética e Direitos Humanos ${ }^{12}$.

A última e mais recente revisão da Declaração de Helsinque, ocorrida em 18 de outubro de 2013, em Brasília, nada alterou com relação ao uso de placebo em pesquisas para doenças com tratamentos já comprovados. Fez apenas mudanças para uma abordagem mais sistemática quanto ao uso de placebos, incluindo no texto da Declaração a possibilidade de haver intervenções menos eficazes do que a da melhor intervenção comprovada e o não tratamento do grupo de controle, desde que devidamente justificáveis metodologicamente ${ }^{13}$. Isso mantém os problemas éticos e não resolve o problema da vulnerabilidade dos participantes dos estudos.

O Brasil manteve seu posicionamento no sentido de não mais adotá-la como norma ética em pesquisa, já que o uso de placebo em situações nas quais existem tratamento eficaz é proibido no País segundo a Resolução do Conselho Nacional de Saúde n. 408/08, incorporada pela nova Resolução CNS n. 466/12, que se manifesta contrária a tais tipos de pesquisa, e o Conselho Federal de Medicina, por meio da Resolução CFM n. 1885/08, que restringe o uso de placebo $^{13}$.

Quando se trata da vulnerabilidade na área das pesquisas com seres humanos, não se pode esquecer que, em decorrência do fenômeno da globalização, a internacionalização das investigações é um fato corriqueiro para muitos países. A vulnerabilidade dos povos da América Latina enseja, então, que os princípios bioéticos sejam utilizados como forma de normatização geral e internacional de forma mais rígida em suas nações, tendo uma interpretação voltada à realidade social, econômica e cultural locais, privilegiando a informação para que se obtenha efetivamente um consentimento livre e esclarecido das pessoas participantes, bem como que os resultados positivos das pesquisas sejam voltados para o benefício das pessoas que vivem nos países onde elas foram desenvolvidas. Além disso, deve-se repensar como se dará a responsabilização dos profissionais da saúde que conduzem as referidas pesquisas.

\section{A responsabilidade dos investigadores e profissionais da saúde na condução das pesquisas com seres humanos}

Como se pode perceber, os dilemas éticos e os conflitos na biomedicina surgem, muitas vezes, em virtude de interesses econômicos, mormente se considerado o poder da indústria transnacional farmacêutica que lidera o campo das investigações, a qual pode, inclusive, distorcer os resultados da pesquisa, configurar as amostras, 
usar equivalentes simbólicos inertes (placebos) para alcançar seus fins estritamente comerciais.

Quando se tratam de pesquisas, a responsabilidade do pesquisador inicia-se com a elaboração do projeto e se estende aos integrantes dos comitês de ética, cujo trabalho não termina com a aprovação de um protocolo, mas com a recepção do relatório final, uma vez que ele se torna corresponsável pelo desenvolvimento das investigações, pois deve acompanhá-las, supervisioná-las e cuidar para que ocorram de forma transparente e responsável pela proteção dos direitos dos envolvidos. Assim sendo, a responsabilidade estende-se a distintos atores que participam desse processo, dentre eles também aos profissionais da saúde que auxiliam na condução das investigações tomando o consentimento dos participantes, prestando informações e ministrando medicamentos.

Nessa área, não são raras às vezes em que se fala de ética e responsabilidade da ciência em detrimento de ética e responsabilidade dos cientistas, o que é equivocado, pois a ciência é um "conjunto de redes conversacionais dos cientistas aceitas pela comunidade que Ihes reservam papel decisório em disputas das mais cotidianas" (p. 97 $)^{14}$. Esses interlocutores parecem esquecer que a ciência é um conjunto de atividades daqueles que as constroem e que a elas se dedicam, que não se pode conceber uma ciência absoluta, assim como uma liberdade absoluta do cientista, pois ele tem deveres para com a sociedade e não somente com o fazer científico. Nesse norte, Pegoraro refere que:

(...) a ciência não é um poder único e absoluto nem o pesquisador é um solipsista, distante do que ocorre no mundo (...) a liberdade do pesquisador não se fecha e não termina no laboratório, mas se articula com a liberdade dos cidadãos. Por isso, a produção científica tem um profundo sentido social (p. 60) $)^{15}$.

O conhecimento científico não pode ser a simples acumulação de dados e informações. Deve ser a articulação desses dados e informações considerando algum interesse social, de modo que ele deve ser adquirido e repassado sempre com vistas ao bem-estar social, passível de tornar-se um poder imoral. As pessoas que detêm o conhecimento sobre determinado assunto são consideradas profissionais por deterem um saber formal, cultivado nas universidades e renovado nas pesquisas ${ }^{16}$. Com base nesse entendimento, são considerados profissionais da saúde para fins deste artigo todos aqueles que participam do desenvolvimento das pesquisas com seres humanos. Além disso, uma característica das profissões modernas é a discricionariedade na utilização do conhecimento, de modo que se faz necessária uma regulação do uso desse conhecimento em forma de códigos éticos para regular o comportamento dos referidos profissionais, pois "a ética é o reino da razão prática"16. O poder associado ao conhecimento pode ter distintas expressões e sua aplicação pode se dar de diferentes formas considerando o local e o tempo, bem como ser desigualmente distribuído entre os próprios profissionais e também entre aqueles que recebem ou partilham do conhecimento adquirido. $\mathrm{O}$ agir pode ter diferentes modulações e significados, por isso a liberdade de agir deve estar ligada à consciência moral e o exercício de uma profissão baseado na prudência frente às incertezas do dia a dia, o que qualifica uma reflexão ética e sua vinculação com a ciência.

Os profissionais da saúde detêm o conhecimento e, portanto, o poder de agir, e somente agirão com responsabilidade se o fizerem com observância do seu dever para com o próximo, pois

Ser responsável significa, por um lado, responder aos valores éticos que o indivíduo assume como pessoa inserida em determinado contexto social e, por outro, responder às consequências de suas decisões. A responsabilidade proporciona independência de coações externas, ao mesmo tempo em que se vincula interiormente de forma livre e lúcida a valores éticos (p. 237) ${ }^{17}$.

A atuação desses profissionais na investigação clínica, em especial para teste de novos medicamentos deve observar cuidadosamente o benefício coletivo potencial que a investigação produzirá frente aos riscos que os sujeitos estão implicados. Além disso, deve reduzir o número de pessoas expostas a esse risco sem prejudicar 
a validez da investigação, sempre estimulando a proteção da segurança dos direitos dos pacientes. Outrossim, sempre deve considerar como alvo de maior proteção as pessoas que possuem uma autonomia reduzida ou diminuída por qualquer razão, ou seja, os vulneráveis, que devem ser previamente informados e esclarecidos pelos profissionais que estão conduzindo as pesquisas. A autonomia deve ser compreendida de forma vinculada com o princípio da responsabilidade, prevendo as consequências futuras das decisões tomadas ${ }^{18}$.

É sabido que os êxitos da medicina contemporânea dependem da tecnologia. Entretanto, deve-se tomar o cuidado para que os profissionais da saúde, bem como os investigadores não fiquem à mercê dos interesses das indústrias farmacêuticas, que dirigem os rumos das investigações e da inovação tecnológica de acordo com sua vontade econômica, o que pode converter a medicina e a ciência em vítimas de seus próprios êxitos, como refere Callahan ${ }^{19}$, e a sociedade refém de todo esse sistema que se cria em torno do lucro das multinacionais.

Daí a importância de os profissionais da saúde avaliarem moralmente as novas tecnologias e não somente buscarem sua utilização baseada em uma simples eficácia clínica, primando por visualizar suas implicações éticas e sociais, pois existem diversos tipos de interesses envoltos na incorporação tecnológica, os quais podem constituir-se em fonte de conflitos e em ferimento aos direitos humanos.

A informação antes e durante a realização das investigações é importante para viabilizar que o investigado participe também da produção do conhecimento e da apropriação dos saberes obtidos, compartilhando responsabilidades. Os participantes, por colaborarem para a produção de novos conhecimentos, merecem proteção, para o que a atuação dos Comitês de Ética, dos pesquisadores e dos profissionais da saúde com relação à maximização dos benefícios e minimização dos riscos deve ser priorizada.

Por isso, não somente os integrantes dos Comitês de Ética, mas os pesquisadores em si e os próprios participantes devem estar preparados e ter uma formação que permita realizar seus papéis com integridade e respeito, além de com fidelidade ao ethos profissional, sempre preocupados em prevenir e reparar danos com responsabilidade, evitando o avanço de uma ciência sem consciência, contribuindo para a emancipação humana com a superação das condições desfavoráveis da vida que impelem as pessoas a situações de vulnerabilidade.

A responsabilidade dos profissionais da saúde não deve ser somente vista e refletida sobre suas ações atuais, mas também considerando suas consequências a longo prazo. Para isso, eles devem conhecer os Códigos de Ética de suas profissões e ter os limites de seu agir estabelecidos também em uma legislação de natureza jurídica, onde poderão ser fixadas penalidades para os casos de violações de direitos que possam vir a ocorrer, o que Ihe implicará uma maior ética de responsabilidade.

\section{CONCLUSÃO}

O estudo atingiu seu objetivo na medida em que se pode refletir acerca da vulnerabilidade dos povos latino-americanos frente à indústria farmacêutica e ao poder do conhecimento técnico-científico na área da biomedicina, bem como acerca da responsabilidade dos profissionais da área da saúde na condução e desenvolvimento de investigações que tenham como objeto da pesquisa seres humanos.

Concluiu-se que o agir desses profissionais deve ser pautado pela ética, de modo que o conhecimento dos Códigos de Ética das respectivas profissões mostra-se imprescindível, mas que as normas dessa natureza têm-se mostrado insuficientes para proteger os direitos dos envolvidos nas pesquisas, o que leva a crer que se faz necessária a elaboração de um documento que abranja a América Latina e de cunho jurídico para impor limites a atuação dos profissionais da saúde nas investigações biomédicas que envolvam seres humanos, pois com as modificações sofridas, a Declaração de Helsinque perdeu sua força normativa e norteadora neste continente. Em virtude disso, uma normatização, não somente ética, mas também jurídica, faz-se premente e importante para que se tenha um continente menos vulnerável e mais solidário. 


\section{REFERÊNCIAS}

1. Lolas F. Ética e ensaios clínicos: perguntas e dilemas. In: Novaes MRG, Lolas F, Quezada A, organizadores. Ética e farmácia: uma abordagem latino-americana em saúde. Brasília: Thesaurus; 2009. p. 256-7.

2. Lorda PS, Cantalejo IMB. Un marco histórico para una nueva disciplina: la bioética. Med Clin. 1995;105:583-97.

3. Peretti C. Gênero, vulnerabilidade e HIV/AIDS: um olhar fenomenológico. In: Sanches MA, Gubert IC, organizadores. Bioética e vulnerabilidade. Curitiba: UFPR / Champagnat; 2012.

4. UNESCO. Declaração Universal sobre Bioética e Direitos Humanos. 2006 [acesso 25 Jan 2014]. Disponível em: http:// unesdoc.unesco.org/images/0014/001461/146180por.pdf.

5. Declaração de Helsínquia da Associação Médica Mundial (versão de outubro de 2013) [acesso 25 Jan 2014]. Disponível em: http://www.uc.pt/fcdef/Comissao de etica/Documentos/Nova Helsinquia.

6. Kottow M. Comentários sobre bioética, vulnerabilidade e proteção. In: Garrafa V, Pessini L, organizadores. Bioética, poder e injustiça. 2nd ed. São Paulo: Centro Universitário São Camilo / Edições Loyola / Sociedade Brasileira de Bioética; 2004.

7. CIOMS. Council for International Organizations of Medical Sciences. International Ethical Guidelines for Biomedical Research Involving Human Subjects, Guideline 13. Geneva, Switzerland; 2002 [cited 2014 Jan 25]. Available from: www. cioms.ch.

8. Macklin R. Bioética, vulnerabilidade e proteção. In: Bioética: poder e injustiça. 2a ed. São Paulo: Sociedade Brasileira de Bioética / Centro Universitário São Camilo / Edições Loyola; 2004.

9. Martins AA. Bioética, saúde e vulnerabilidade: em defesa da dignidade dos vulneráveis. São Paulo: Paulus; 2012.

10. Rauli PMF, Tescarolo R. Bioética, vulnerabilidade e educação. In: Sanches MA, Gubert IC, organizadores. Bioética e vulnerabilidades. Curitiba: UFPR / Champagnat; 2012.

11. Guilhem D, Novaes MRG. Ética e investigação em seres humanos. In: Novaes MRG, Lolas F, Quezada A, organizadores. Ética e farmácia: uma abordagem latino-americana em saúde. Brasília: Thesaurus; 2009.

12. Garrafa V, Lorenzo C. Helsinque 2008: redução de proteção e maximização de interesses privados. Rev Assoc Med Bras. 2009 [acesso 25 Jan 2014];55(5):514-8. Disponível em: http://www.scielo.br/scielo.php?script=sci arttext\&pid=S0104-42302009000500010\&lng=pt\&nrm=iso\&tlng=pt. DOI: http://dx.doi.org/10.1590/S0104-42302009000500010.

13. Hellmann F. Declaração de Helsinque versão 2013 é adotada na Assembleia Geral da Associação Médica Mundial. 2013 [acesso 25 Jan 2014]. Disponível em: http://www.sbbioetica.org.br/noticia/declaracao-de-helsinque-versao-2013-e-adotada-na-assembleia-geral-da-associacao-medica-mundial/.

14. Luz M. Ética e Ciência 3. Racionalidades Médicas e Bioética. In: Palácios M, Martins A, Pegoraro AO, organizadores. Ética, ciência e saúde: desafios da bioética. Petrópolis (RJ): Vozes; 2001.

15. Pegoraro OA. Ética e ciência 1. Fundamentos filosóficos da bioética. In: Palácios M, Martins A, Pegoraro AO, organizadores. Ética, ciência e saúde: desafios da bioética. Petrópolis (RJ): Vozes; 2001.

16. Lolas F. Bioética en América Latina: una década de evolución. Santiago: Centro Interdisciplinario de Estudios en Bioética, Universidad de Chile. Programa de Bioética - OPS/OMS; 2010.

17. Guilhem D, Novaes MRG. Ética e investigação em seres humanos. In: Novaes MRG, Lolas F, Quezada A. Ética e farmácia: uma abordagem latino-americana em saúde. Brasília: Thesaurus; 2009.

18. Waldow VR, Borges RF. O processo de cuidar sob a perspectiva da vulnerabilidade. Rev Lat Am Enfermagem. 2008 [acesso 25 Jan 2014];16(4):765-71. Disponível em: http://www.scielo.br/scielo.php?script=sci_arttext\&pid=S0104-11692008000400018\&lng=en\&nrm=iso\&tlng=pt. DOI: http://dx.doi.org/10.1590/\$0104-11692008000400018.

19. Callahan D. The goals of medicine. Setting new priorities. Hastings Center Report. 1996;26(6):1-26. 